\title{
A SURVEY OF FAMILY PLANNING IN THE PHILIPPINES
}

\author{
F. E. RIPHAGEN*, O. S. DE LA CUEVA† AND S. KOELB* \\ *International Health Foundation, Geneva Brussels, and \\ $\dagger$ Family Planning Organization of the Philippines
}

\begin{abstract}
Summary. In a multi-centre survey in 1986, 400 married Filipino women aged 15-40 were interviewed about their use of contraceptive methods, and specifically about their perceptions of the effects on health of oral contraceptives and their attitudes to contraceptive methods. The sample was randomly selected in the urban and rural areas surveyed and cannot be considered representative for the country as a whole. The results showed that women hold definitive views on the health risks posed by oral contraceptives and point to the importance of family planning clinics as a source of contraceptive counselling. The overall rate of contraceptive use must be regarded as insufficient to meet contraceptive needs.
\end{abstract}

\section{Introduction}

In the early months of 1986, a survey was conducted in the Philippines as part of a joint project by Family Health International (FHI) and the International Health Foundation (IHF), designed to obtain information on opinions on the pill held by women in selected developing countries. The results of this 'opinion poll' have been published (Report of the Perceptions of the Pill Survey Group, 1987). The present study in the Philippines covered additionally elements of family planning, such as contraceptive use, demographic and socioeconomic factors that may influence contraceptive use, communication and the role of professional counselling.

The fieldwork for the study was organized and co-ordinated by the Family Planning Organization of the Philippines. The results provide information on contraceptive practices in that country, as well as on the factors influencing those practices.

\section{Method and subjects}

The samples were drawn from available local authority registers in both urban and rural communities. The registers are lists of all married couples of reproductive age living in each barangay; they are compiled by the National Population Programme and can be used by every family planning or other organization that might need them. For every district or area, as classified by the National Census and Survey Office, the barangays to be studied were selected by a random procedure. Sampling was 
Table 1. Age distribution of women in total sample

\begin{tabular}{cccc}
\hline $\begin{array}{c}\text { Age group } \\
\text { (years) }\end{array}$ & $\%$ of sample & $\begin{array}{c}\text { Age group } \\
\text { (years) }\end{array}$ & $\%$ of sample \\
\hline $15-20$ & 1 & $31-35$ & 27 \\
$21-25$ & 15 & $36-40$ & 27 \\
$26-30$ & 30 & & \\
\hline
\end{tabular}

performed according to the principles of multi-stage cluster sampling and systematic sampling with a random start. The studied group can be considered as representative for the population of the areas under study but not for the country as a whole.

The women who took part in the study $(n=400)$ were living in one of ten urban communities in Metro Manila or ten rural communities in the Nueva Ecija Province. Five of the urban areas surveyed were inhabited predominantly by low income families and five by families who could be classified as middle income. In the rural areas selected, socioeconomic levels were not directly measurable by income; they were subsequently determined by estimating annual crop yields and current market prices. All the women were married $(99 \%)$ or cohabiting $(1 \%)$ and were aged $15-40$ years, the majority over 25 years, with a mean age of 31.5 (Table 1). The women were questioned by trained interviewers.

Women of a higher social class and resident in urban areas were the most reluctant to participate of those interviewed, while women from rural areas were sometimes reluctant to divulge information about their contraceptive practices. Apart from this, no major problems were encountered.

The questionnaire used consisted of 21 'closed'-type questions. The survey dealt with demographic information including age, parity, number of living children, level of education of husband and partner, monthly income and type of residence. Women were asked about their contraceptive practices in the past, the present and the foreseeable future, their reasons for changing or abandoning methods of contraception, and about their future plans regarding family size. Other questions

Table 2. Distribution of sample by parity, number of living children and age of youngest child

\begin{tabular}{lccccc}
\hline Parity & \% of sample & $\begin{array}{c}\text { No. of living } \\
\text { children }\end{array}$ & $\%$ of sample & \multicolumn{2}{c}{$\begin{array}{c}\text { Age of youngest } \\
\text { child (years) }\end{array}$} \\
\hline 0 & 4 & 0 & 4 & 51 & 27 \\
1 & 14 & 1 & 16 & 2 & 17 \\
2 & 21 & 2 & 23 & 3 & 12 \\
3 & 24 & 3 & 25 & 4 & 44 \\
4 & 17 & 4 & 17 & & \\
5 & 12 & 5 & 8 & & \\
6 & 8 & 6 & 7 & & \\
\hline
\end{tabular}


related to the use of contraceptive counselling, the source of professional advice, and allocation of responsibility for the actual choice of method. Finally, women were asked about their perceptions of the health effects of oral contraception and about how those perceptions compared to the perceived risks of childbearing.

The majority of the women taking part in the survey had two to four living children, mean 2.9 children (Table 2). The ages of the youngest children reflect the mean sample age, 31.5 years. Though relatively old, $32 \%$ of respondents indicated that they still wanted another child. The number of children is lower than the desired family size of $4 \cdot 2$ children and the actual total fertility rate of 5.3 children determined in the Philippines by the World Fertility Survey in 1978 (World Fertility Survey, 1979), the figure for the mean number of children at present being distinctly lower, as is to be expected from the difference in the variables employed.

Table 3. Educational level of women and their partners

\begin{tabular}{lcc}
\hline Years in school & $\begin{array}{c}\text { Women } \\
\%\end{array}$ & $\begin{array}{c}\text { Husbands } \\
\text { (partners) } \\
\%\end{array}$ \\
\hline Less than 7 & 39 & 31 \\
$7-11$ & 41 & 45 \\
More than 11 & 19 & 23 \\
None & 1 & 1 \\
\hline
\end{tabular}

Apparently the sexes differed little in the distribution of their levels of education (Table 3). Lower and middle educational levels prevail, also as a result of area selection, with a mean of 8.1 years of completed formal education.

Table 4. Family income

\begin{tabular}{lc}
\hline Pesos/month & $\%$ \\
\hline Less than 1000 & 58 \\
$1000-2500$ & 30 \\
More than 2500 & 12 \\
\hline
\end{tabular}

100 pesos $=5 \cdot 30$ US\$ (January 1986).

Monthly family income (Table 4) was reported directly in the urban areas surveyed, but in the rural areas it was calculated subsequently.

\section{Results}

Contraceptive methods used

Two hundred and twenty-five women $(56 \%)$ used no method of contraception. Fifty-nine women $(14 \%)$ had either been sterilized for contraceptive purposes 
Table 5. Contraceptive use rates corrected for double use

\begin{tabular}{lccc}
\hline \multicolumn{1}{c}{ Method used } & $\begin{array}{c}\text { IHF (1986)* } \\
\%\end{array}$ & $\begin{array}{c}\text { NDS (1983) } \\
\%\end{array}$ & $\begin{array}{c}\text { WFS (1978) } \\
\%\end{array}$ \\
\hline None, other methods not stated & 55 & 69 & 64 \\
Pill & 19 & 6 & 5 \\
Sterilization (both sexes) & 14 & 10 & 6 \\
IUD & 1 & 2 & 2 \\
Barrier methods & 3 & 2 & 4 \\
Withdrawal & 5 & 4 & 10 \\
Rhythm & 3 & 7 & 9 \\
Total & 100 & 100 & 100 \\
\hline
\end{tabular}

Data sources: * International Health Foundation, married or cohabiting women, $15-40 ; \dagger$ National Demographic Survey, ever married women, $15-49 ; \ddagger$ World Fertility Survey, ever married women, 15-49.

themselves or their husbands had undergone vasectomy. Seventy-seven women (19\%) took the pill and seven (2\%) used an IUD. Only one respondent used a long-acting injectable. Three respondents used spermicides and 21 couples $(5 \%)$ used condoms. Rhythm was practised by 25 couples $(6 \%)$ and withdrawal by 30 men $(8 \%)$.

Double utilization was observed with condoms, spermicides, rhythm and withdrawal, not unlike patterns observed in western Europe, e.g. in Italy (Riphagen, van der Vurst \& Lehert, 1984). Altogether $27 \%$ of the users in this sample used more than one method. For purposes of analysis, the use rates within the sample were corrected for double use by recording the method first mentioned and leaving out the other(s). Spermicides and condoms were categorized together, as were oral contraceptives and injectables. Contraceptive use rates corrected for double use are shown in Table 5, where they are compared to use rates obtained by the 1983 National Demographic Survey (University of the Philippines Population Institute, 1984) and by the 1978 National Fertility Survey (Carrasco, 1981; Johns Hopkins University, 1982, 1983). Though comparison is difficult due to the differences in sampling, some observations will be made.

While $32 \%$ of the women questioned indicated that they wanted another child, $55 \%$ did not use any method of contraception. Even if one makes the (speculative) assumption that those desiring another child wanted to conceive right away, this rate of contraceptive use $(45 \%)$ must be considered insufficient, although superior to that in 1978, and at the same level observed in 1982 (Lapham \& Mauldin, 1985). The existing data are evidently not consistent: the World Fertility Survey found $36 \%$ overall use of contraception in 1978, Lapham \& Mauldin (1985) $45 \%$ in 1982, and the National Demographic Survey (1984) 32\% in 1983, all based on similar sampling.

The use of oral contraception and the rate of sterilization are higher in this sample than they were in the 1978 and 1983 studies. Use of the IUD and condoms (barrier methods) are at the same level as previously, while rhythm and withdrawal are much less widely practised than was the case in the 1978 and 1983 studies. All in all, the 
Table 6. Duration of contraceptive use (all methods) by present users

\begin{tabular}{lr}
\hline & $\%$ \\
\hline$<1$ year & 28 \\
$1-3$ years & 26 \\
$>3$ years & 46 \\
\hline
\end{tabular}

present findings indicate that the study sample can be considered fairly 'modern' in regard to contraceptive use, although non-use was still considerable.

The duration of contraceptive use by current users is shown in Table 6. Almost half of the women had been using a method for more than 3 years. This level of previous experience reflects the age distribution in the sample, but also indicates a consistent acceptance of family planning.

\section{Differentials of current contraceptive use}

Domicile. Overall differences between urban and rural areas were not great, nor were they statistically significant. IUD use (very low already) was limited to the urban areas, where rhythm also seemed to be slightly more popular than in rural areas.

Differences were sometimes evident between the communities, thus non-use was higher than average in San José but lower than average in Tondo. Pill use was below average in Quezon City but above average in Munoz. Withdrawal seemed to be popular in Makati but not in Quezon City, while rhythm was most widely practised in Tondo $(P=0.04)$.

Age. Non-use decreased with rising age, while, not surprisingly, the sterilization rate increased $(P=0.004)$. Pill use was at a peak between the ages of 25 and 30 years $(28 \%)$ and then decreased with age, a pattern similar to that in Western countries (Riphagen et al., 1984; Riphagen, van der Vurst \& Lehert, 1985a,b, 1986a,b).

Rhythm and withdrawal were more widely practised by both the younger and older (36-40) age groups, while barrier method use varied little with age. This also resembles use patterns in some Western countries, e.g. Spain and Italy.

Number of living children and age of the youngest child. As might be expected, a pattern was observed similar to that for age. Pill use was highest in two- or three-child families, with sterilization being most frequent in four-child families, who also reported the lowest level of non-use $(P=0.001)$.

Levels of method use in general showed a weak positive correlation with the age of the youngest child, not unexpected since the age of the youngest child also shows a correlation with the age of the mother.

Education. No variation of non-use of contraception or choice of method was observed with differing levels of education of both partners.

Monthly income. This socioeconomic indicator had the greatest observed influence in the middle income group: non-use was lower but rhythm and withdrawal were higher $(P=0.03)$. The higher income group had a slightly higher use rate for the pill, while the lowest income category showed a lower rate of barrier method use. 
Past use of contraceptive methods and reasons for change. The majority $(67 \%)$ of users in the study had used another method of contraception before the present one. The analysis suggested a sequential trend of non-use, pill use and, finally, sterilization. This is a quite familiar pattern of birth spacing, beginning with intermittent pill use and ending with sterilization, observed, for example, in western Europe (Riphagen $e t$ al., 1984a,b, 1985a,b). The pill is apparently a preferred method for birth spacing in the Philippines as well.

The reasons given for a change in method were also similar to those given in Western countries: health reasons preceded considerations of reliability, and these were the only motives considered important. A minority $(21 \%)$ of the current users surveyed were already sure that they would change their method in future. Sterilization was most frequently mentioned as the future method decided upon.

\section{Communication and choice}

Of the women studied, $77 \%$ had at some time sought advice on contraception. The sources of advice are shown in Table 7. These sources of advice are almost exclusively professional. The influence of family planning institutions is clearly great. Among those who consulted a private or government doctor for family planning there were fewer women than average who used no contraception or had practised withdrawal. All other methods, including rhythm, were more frequently used than in the sample as a whole. Those who went to government doctors made less use of the pill and greater use of barrier methods and the IUD. The pattern for those who attended family planning clinics was almost the reverse: more frequent pill use and less condom use $(P=0.014)$.

Table 7. Sources of advice on contraception

\begin{tabular}{lr}
\hline & $\% *$ \\
\hline Family planning clinics & 55 \\
Doctors (private) & 12 \\
Doctors (in government employment) & 29 \\
Others & 4 \\
\hline
\end{tabular}

*\% of those who had ever sought advice on contraception.

The women were asked who had taken the decision on the choice of contraceptive method, or whether not to use contraception (Table 8). The women were very conscious of where, in their opinion, the responsibility for family planning rested: either with the couple or, if not, then with themselves. Whenever the partner was mentioned as the deciding party, the use of barrier methods and the practice of rhythm and withdrawal were more frequent $(P=0.03)$. Women choosing on their own more often use the pill $(P=0.04)$. Though questions of this kind are often considered less suitable because the answers may be biased by 'social desirability', the responses 
Table 8. Responsibility for choosing contraceptive methods

\begin{tabular}{lr}
\hline & $\%$ \\
\hline Woman alone & 39 \\
Partner & 12 \\
Both & 48 \\
Doctor & 1 \\
Family planning clinic & 0 \\
Others & 0 \\
\hline
\end{tabular}

indicate a strong notion that family planning is an important responsibility of the couple.

\section{Perceptions of the health effects of oral contraceptives}

In many countries rumours circulating about the pill's safety present a picture that can hardly be considered favourable to its use (Riphagen et al., 1984a,b, 1985a,b; Report of the Perceptions of the Pill Survey Group, 1987; American College of Obstetricians and Gynecologists and Gallup, 1985). The multi-country study carried out by FHI and IHF aimed to trace relevant opinion in a number of developing countries. To this end several (as few as possible) questions were formulated for inclusion in the survey (Report of the Perceptions of the Pill Survey Group, 1987). These questions focused primarily on the supposed negative health effects of the pill.

The majority ( $76 \%$ ) of Filipino women interviewed knew other women who took the pill, and $17 \%$ claimed to know one or more users who had fallen ill because of oral contraceptives. Twenty-five per cent of respondents stated that the pill poses important health risks, $64 \%$ that the pill does not pose important health risks and $11 \%$ did not know. In comparison with opinions on this question in some other developing countries (Report of the Perceptions of the Pill Survey Group, 1987) and in western Europe (Riphagen et al., 1984, 1985a,b, 1986a,b), the present result is quite favourable.

Age, number of children and income had no influence on the results. The proportion in the rural subgroup who did not know was only slightly higher than in the urban group.

Pill users had a more positive attitude towards their own method, which is not surprising. On the other hand, women who had been sterilized (or whose husbands had been sterilized) considered oral contraception to be significantly more dangerous to health $(P=0.01)$. The non-users in the survey, however, did not differ from the average opinion as expressed by the entire sample. Views on alleged specific shortand long-term side effects are shown in Table 9. Again respondents were quite outspoken, as can be seen by the relatively low percentage with 'no idea'. The overall mean percentage giving positive answers was about $32 \%$, or slightly over $20 \%$ when less serious reversible side effects (headache, weight gain) are excluded. This corresponds closely with the previous question, where $25 \%$ thought that the pill poses an 'important health risk'. 
Table 9. Perceived disadvantages of oral contraceptives

\begin{tabular}{lcccc}
\hline & \multicolumn{5}{c}{$\%$} \\
\cline { 2 - 5 } & Yes & No & No idea & Total \\
\hline Infertility & 11 & 62 & 27 & 100 \\
Cardiovascular disease & 26 & 53 & 21 & 100 \\
Increased cancer risk & 18 & 56 & 26 & 100 \\
Headache & 61 & 29 & 10 & 100 \\
Weight gain & 65 & 24 & 11 & 100 \\
Increased risk of sexually transmitted diseases & 9 & 68 & 23 & 100 \\
Congenital malformations & 37 & 50 & 13 & 100 \\
\hline
\end{tabular}

The number of respondents who regarded headache and weight gain as a disadvantage of oral contraception was quite high, whereas the $26 \%$ who thought that cardiovascular disease was a risk were fewer than in other countries surveyed (Report of the Perceptions of the Pill Survey Group, 1987), and so were those who thought that there was increased cancer risk. Infertility and sexually transmitted diseases were less frequently thought to be implicated as compared, for instance, with either western Europe or some other developing countries (Riphagen et al., 1984, 1985a,b, 1986a,b; Report of the Perceptions of the Pill Survey Group, 1987). Perceptions regarding birth defects stand out as a clear exception in this list of scores. The $37 \%$ who think that the pill causes birth defects is quite a high figure and not readily explicable in the context of the other results, which, although not always realistic, appear moderate.

Analysis of these results, together with a number of other variables (age, number of children, area, education, contraceptive use and income), showed a moderate number of statistically significant variations. Women from Makati and Tondo (both urban areas), in particular, differed from those living in San José (a rural area) in their views of the risk. of heart disease, headache and birth defects posed by the use of oral contraception. In all three cases, urban women were more pessimistic than their rural sisters $(P<0.05$ for all three). Pill users were less pessimistic than all others in regard to the risk of heart disease and cancer posed by pill use $(P$ values $<0.05)$.

Finally, education and income had some influence on the results for perceptions of the risk of heart disease, cancer and sexually transmitted diseases. For all three categories, either a higher educational level or a higher income level was associated with a more negative view $(P<0.05)$.

Pill or baby?

The final question concerned the balance of risks associated with either pregnancy or delivery against those associated with the use of oral contraceptives. This question is, of course, rather abstract, but despite its difficulty the question is of some interest because it reveals women's opinions (Table 10).

The relative danger to health attributed to pregnancy and childbirth clearly overrides that attributed to oral contraception. This finding differs from that 
Table 10. Perceived health risks of pregnancy and childbirth as compared

to risks of oral contraceptives (\%)

\begin{tabular}{lr} 
Taking the pill carries greater risk & 20 \\
Having a baby carries greater risk & 61 \\
Risks are equal & 17 \\
No risk at all & 2 \\
\hline
\end{tabular}

observed in other countries, including the United States (Report of the Perceptions of the Pill Survey Group, 1987; Riphagen, 1987; American College of Obstetricians and Gynecologists and Gallup, 1985). Further analysis with other variables also revealed that pill users, specifically, consider childbirth and pregnancy more dangerous to a woman's health than is pill use, and vice versa $(P=0.02)$. Urban women, especially those living in Makati and Tondo, tended to the opinion that the pill is more dangerous than having a baby to a greater degree than the average sample $(P=0.04)$.

\section{Conclusions}

In the sample of 400 women surveyed for this study, half of whom lived in Metro Manila and half outside the city in the Nueva Ecija Province, contraceptive use was found to be $45 \%$. As only $32 \%$ of the women surveyed stated that they wanted another child, the total use rate must be considered insufficient.

Oral contraception $(19 \%)$ and sterilization $(14 \%)$ were the most frequently used methods of birth control. A tendency towards the use of oral contraceptives as a birth spacing method, common in Western countries, was also observed in this sample. Age and number of children had an influence on the use rates of the various methods very similar to that observed in European countries. Pill use was found to be highest among women in their late twenties with two or three children. Urban-rural differences and socioeconomic factors had little influence.

The majority of contraceptive users had been using their present method for at least 1 year. There appeared a trend, similar to that found in western Europe, from no specific method at first, then to oral contraception, ending with sterilization. Family planning clinics were the most important source of contraceptive counselling, and the choice of a particular method rested with the woman, in conjunction with her husband.

Perceptions of the alleged negative effects on health of oral contraceptives were, with one exception (birth defects), less negative than elsewhere, although the number of respondents viewing the pill negatively was not negligible. Since most respondents went to family planning clinics, it can be concluded that the professionals working in these clinics pay close attention to the transmission of this type of information, although the image of oral contraception could still be updated and made to correspond more closely to current medical knowledge.

Filipino couples seem to be aware of the importance of family planning on an individual and couple basis. The joint effort score of family planning programmes in 
the Philippines was classified by Lapham \& Mauldin (1985) as moderate, with 17 developing countries obtaining higher scores but 83 others lower. Education and information of eligible couples have long since been recognized as the over-rulingly important elements of family planning programmes. However, acceptors of contraceptive methods also need confidence in the methods offered.

Information concerning the risks and benefits of advanced contraceptive methods such as the pill and the IUD, mostly generated through studies conducted in Western countries, is not necessarily suited to developing countries like the Philippines, where it is often spread by the mass media. Instead, in developing countries, the benefits of contraceptive methods should be emphasized against the background of the very real and familiar health hazards such as high maternal and infant mortality, obstetrical risks, malnutrition and iron deficiency anaemia.

\section{References}

American College of Obstetricians and Gynecologists and Gallup (1985) Summary of the Poll on American Attitudes and Knowledge of Contraception. Gallup, USA.

Carrasco, E. (1981) Contraceptive Practice. World Fertility Survey Comparative Studies. International Statistical Institute, The Hague.

Johns Hopkins University $(1982,1983)$ Population Reports. Series A No. 6, Series D No. 4, Series H No. 6, Series B No. 4. Baltimore.

LAPHAM, R. J. \& MAULDIN, W. P. (1985) Contraceptive prevalence: the influence of organized family planning programs. Stud. Fam. Plann. 16, 117.

Report of the Perceptions of the Pill Survey Group (1987) Women's perceptions of the safety of the pill: a survey in eight developing countries. J. biosoc. Sci. 19, 313.

RiphaGEN, F. E. (1987) The image of the pill, a remarkable social change. In: Oral Contraception in Perspective. Parthenon Press, Carnforth.

Riphagen, F. E., van Der Vurst, J. \& Leher T, P. (1984) Contraception in Italy: International Health Foundation, Geneva.

Riphagen, F. E., VAN Der VUrST, J. \& Lehert, P. (1985a) Contraception in France. International Health Foundation, Geneva.

Riphagen, F. E., VAN DeR Vurst, J. \& Lehert, P. (1985b) Contraception in Great Britain. International Health Foundation, Geneva.

Riphagen, F. E., van der Vurst, J. \& Lehert, P. (1986a) Contraception in Spain. International Health Foundation, Geneva.

Riphagen, F. E., van der Vurst, J. \& Lehert, P. (1986b) Contraception in the Federal Republic of Germany: International Health Foundation, Geneva.

WORLd Fer TILITy SURvey (1979) The Republic of the Philippines Fertility Survey: A Summary of the Findings. International Statistical Institute, The Hague. 